\title{
CONSIDERAÇÕES SOBRE O PREFIXO RE-
}

\begin{abstract}
Alessandro Boechat de MEDEIROS*
- RESUMO: O presente trabalho investiga as propriedades morfossintáticas, morfológicas e semânticas do prefixo re- do português brasileiro assumindo o arcabouço teórico da Morfologia Distribuída. Busca-se, assim, estabelecer sua distribuição e sua contribuição semântica nos contextos em que ocorre. O artigo apresenta evidências de que o prefixo em questão modifica (repete) estados que tipicamente decorrem de eventos incluídos nas denotações dos verbos, nos quais a prefixação é licenciada. Assumindo estruturas de evento sintaticamente representadas, é possível entender a distribuição do prefixo e explica-se a interpretação do verbo prefixado, usando a ideia de escopo do prefixo na estrutura de evento associada ao verbo de base: na proposta, o prefixo terá escopo sobre a parte da estrutura que denota o estado atingido. O prefixo não será encontrado em verbos que não estejam associados a estruturas de evento que incluam um estado em sua denotação. Uma vez que estados nas estruturas de evento podem ser veiculados por adjetivos, raízes puras e certos tipos de sintagmas preposicionais, e que o prefixo é licenciado pela presença dessas estruturas, a aposta será de que o prefixo não faz seleção categorial.
\end{abstract}

- PALAVRAS-CHAVE: Prefixo re-. Morfologia distribuída. Estrutura de eventos.

\section{Introdução}

Neste trabalho, proponho-me a investigar a natureza do prefixo re-, com a interpretação dicionarizada de "repetição" (HOUAISS, 2009), usando o arcabouço teórico da Morfologia Distribuída (HALLE; MARANTZ, 1993; MARANTZ, 1997). Pretendo entender sua distribuição e sua exata contribuição semântica nas estruturas verbais em que ocorre. Faço ainda algumas comparações de suas propriedades com as do prefixo des-, conforme ideias desenvolvidas em Medeiros (2010).

Seguindo propostas de Marantz (2007), para o prefixo re- em inglês, e de Medeiros (2010) para o prefixo des- em português, defendo que o prefixo modifica uma subeventualidade estativa interna aoVP. Para tanto, levarei em consideração algumas ideias, desenvolvidas em Marantz (vários manuscritos) e Scher et al. (2012), sobre as estruturas de evento dos verbos. Assumirei que essas estruturas

* UFRJ - Universidade Federal do Rio de Janeiro. Departamento de Lingüística e Filologia. Rio de Janeiro - RJ Brasil. 21941-901 - alboechat@gmail.com 
são sintaticamente representadas, e que o prefixo re- tem escopo sobre parte dessa representação sintática.

O texto tem a seguinte organização. Na seção a seguir, discuto aspectos da interpretação do prefixo que serão relevantes para a análise. Na sequência, apresento e faço algumas considerações sobre duas abordagens (uma para o prefixo re- do inglês e uma para o advérbio wieder do alemão), aproveitando várias de suas virtudes - mas também apontando seus problemas. Em seguida, proponho uma alternativa de análise. As duas últimas seções se dedicam a mostrar consequências importantes da análise aqui proposta e alguns problemas.

\section{Do significado e dos contextos em que o prefixo re- é licenciado}

Imagine-se a seguinte situação: estou preocupado com problemas que as raízes de uma bela árvore em meu quintal podem estar causando às fundações da minha casa. Juntamente com meu caseiro, cavo a terra em volta da árvore atrás das suas raízes, para expô-las. Expostas as raízes, verifico que elas não estão causando danos à minha casa nem ameaçam suas fundações. Sendo assim, reenterramos as raízes, pois desejo que a árvore continue firme, embelezando meu quintal.

Imagine-se outra situação: achando que a vida na Terra seria melhor se o planeta fosse chato, os homens inventaram uma maneira de transformar o planeta em um disco. Contudo, o resultado da experiência causou tantos danos ao meio ambiente que os homens resolveram criar um processo que recurvasse a Terra, restituindo-lhe a forma original.

Considere-se ainda uma terceira situação: uma caverna teve sua abertura bloqueada por uma avalanche de pedras. Como era uma caverna cheia de pinturas rupestres, aberta à visitação pública e pesquisa arqueológica, pesquisadores e moradores da localidade pressionaram as autoridades para que reabrissem sua entrada, mas com o cuidado necessário à preservação das pinturas rupestres do sítio.

Nos contextos acima, é razoável supor que os eventos de enterrar as raízes, curvar a Terra e abrir a caverna de fato nunca aconteceram antes dos eventos de reenterrar as raízes, recurvar a Terra e reabrir a caverna; tampouco as raízes se enterraram, a Terra se curvou ou a caverna (se) abriu alguma vez. Ora, se o prefixo indicasse repetição do evento descrito pelo verbo de base, seja na sua versão causativa, seja na sua versão incoativa (quando há), o esperado seria que, nos contextos dos parágrafos anteriores, o uso do prefixo fosse semanticamente anômalo, uma vez que é impossível repetir eventos que nunca ocorreram. 
A leitura do prefixo re- em português pode ser, portanto, o que a literatura chama de restitutiva (DOWTY, 1979; STECHOW, 1996; MARANTZ, 2007; entre outros): a ação ou evento denotado pelo verbo prefixado restitui ao seu complemento um estado (este é, portanto, pressuposto). Tendo em mente tal fato, a pergunta que se coloca é se aquilo que a literatura chama de leitura repetitiva (na qual se pressupõe uma ocorrência anterior do evento denotado pelo verbo, realizado pelo mesmo agente) (STECHOW, 1996) também é veiculada pelo prefixo. Uma maneira de verificá-lo é tentar prefixar verbos que denotam atividades, mas em cujo significado não se inclui um estado atingido, como os exemplos a seguir:

(1) Verbos de atividade inergativos: \#recorrer ${ }^{1}$ (significando "correr de novo"), *redormir, *reandar, "recaminhar, \#reagir (significando "agir de novo"), *reviajar, *regritar, "ressorrir, *rerrir, " ${ }^{*}$ repular, etc.

A lista (1) mostra que o prefixo não "repete" qualquer tipo de evento: de nenhum dos itens acima o significado do verbo de base inclui um estado atingível por seu único (nas versões intransitivas) argumento (que é um agente); e, como se vê, são todos inaceitáveis, no sentido pretendido.

Entretanto, o leitor poderia se perguntar se o que proíbe a prefixação dos verbos em (1) não seria o fato de tais verbos não possuírem um complemento em algum momento da derivação ou o fato de denotarem atividades sem um ponto final em seus usos intransitivos (não necessariamente um estado atingido). Apesar de, num certo sentido, tais hipóteses serem verdadeiras, elas não são suficientes para explicar o que se observa sobre a prefixação. Vejam-se os exemplos a seguir:

(2) a. *Ele regritou seu grito de guerra; *ele rerriu sua famosa risada; *ele recantou aquela cantiga na festa; ??ela redançou a valsa dos quinze anos com seu namorado; *o piloto recorreu a corrida de Interlagos.

b. *?Ele recorreu/reandou/recaminhou/repulou dez metros.

c. João reconstruiu casas por anos.

Em (2a), os verbos inergativos ganharam complementos cognatos, quantificados, mas a prefixação ainda é inaceitável ou bastante marginal. Em (2b), aos verbos prefixados acrescenta-se um complemento quantificado, estabelecendo um ponto final para o evento denotado pelo VP; no entanto, uma vez que não se inclui um estado atingido pelo complemento ou pelo

1 O símbolo \# indica que a palavra existe no vocabulário, mas não no sentido pretendido. 
sujeito (inacusativo) do verbo, o uso do prefixo continua impedido ou bastante marginal. Em (2c), por outro lado, a interpretação do VP não inclui um ponto final ${ }^{2}$, mas implica mudança de estado da denotação do complemento, e o prefixo é licenciado.

Aceitando a hipótese de que a categoria semântica "estado" é relevante para o licenciamento do prefixo, a pergunta que imediatamente se coloca é se qualquer verbo cuja semântica inclua um estado aceita o prefixo. Dos itens da lista (3) abaixo, com verbos puramente estativos, vemos que isso não é sempre verdade.

(3) *reamar, "

Observe-se que os verbos acima denotam estados de seus sujeitos, sem implicação de um estado atingido por seus complementos: se João ama/amou Maria, o acarretamento não é que Maria está ou ficou amada. O mesmo vale para odiar, gostar, supor, saber etc.

O quadro até o momento sugere que somente verbos cujo significado inclui um estado atingido pela denotação de seus complementos aceitam a prefixação.

Williams (2006) aponta, ainda, algumas propriedades interessantes do prefixo re- em inglês que também valem para o português. A primeira tem a ver com o que a literatura chama de existential closure: em "João reabriu uma porta", o pressuposto é que uma porta estivera aberta e à mesma porta o estado aberta foi restituído por João. Observe-se que em "João abriu uma porta de novo", não necessariamente a mesma porta fora aberta antes (por João). A segunda é: nenhum advérbio modificador de processo pode estar no escopo de re-. Assim, se digo que João reabriu uma porta rapidamente, não afirmo nada sobre a velocidade com que a porta foi aberta ou se abriu (se isso alguma vez aconteceu) antes de sua reabertura.

Para terminar esta seção, é importante esclarecer que as restrições aqui apontadas para o prefixo re- não se aplicam a advérbios como de novo ou novamente, aparentes correlatos do prefixo. Isso quer dizer que tais advérbios podem ter a leitura repetitiva: posso correr (dez metros) de novo, rir de novo, sentir (dor de cabeça) de novo etc. E mais: os advérbios novamente ou de novo, em sua leitura repetitiva (porque eles também podem veicular a leitura restitutiva), não implicam existential closure do complemento do verbo (ver exemplo acima), e têm escopo sobre advérbios modificadores de processo: assim, se rio agitadamente de novo, o pressuposto é que ri agitadamente antes, não simplesmente que ri antes.

Ainda que os eventos individuais que constituem a eventualidade denotada pelo VP tenham pontos finais intrínsecos. 


\section{Discutindo abordagens}

Stechow (1996) trata do advérbio wieder (novamente) em alemão, mostrando que ele veicula tanto a leitura restitutiva como a leitura repetitiva. Entretanto, diferentemente de trabalhos como Dowty (1979), que trata as diferentes leituras do advérbio again do inglês em termos de postulados de significado, Stechow trata as leituras possíveis associadas ao advérbio wieder como diferenças de escopo dentro de uma estrutura sintática nos moldes da semântica gerativa, como o esquema abaixo mostra:

\section{Esquema 1}

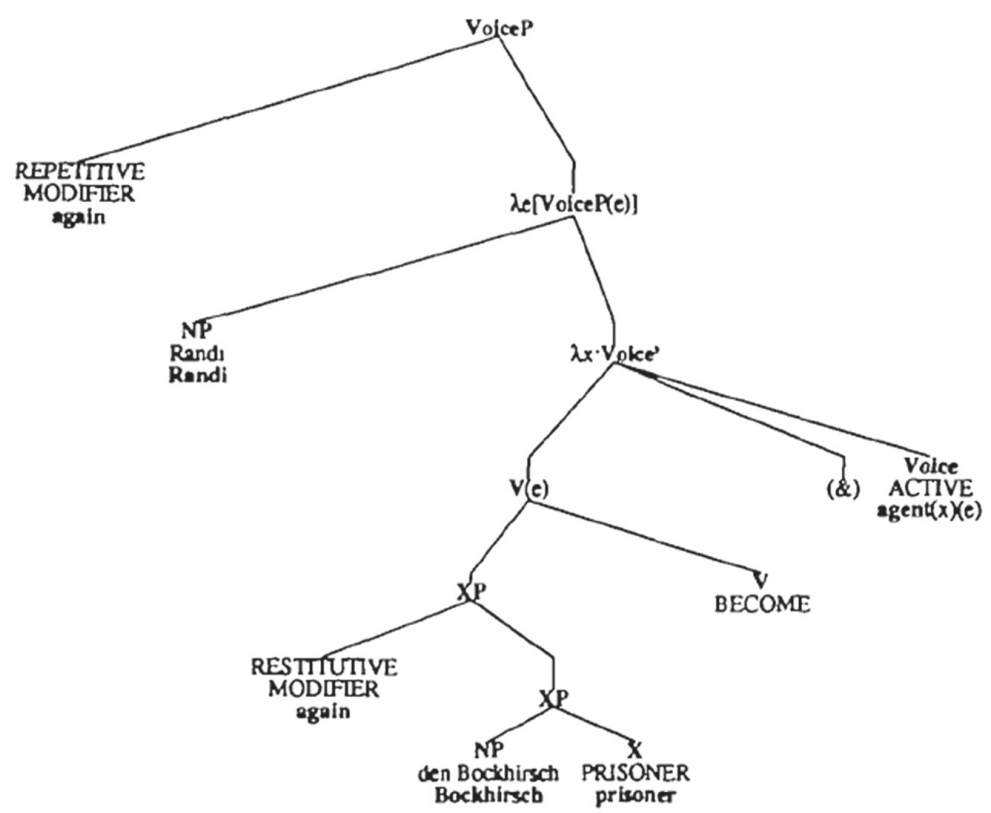

Fonte: Stechow (1996, p.97).

A sentença do exemplo é: Randi den Bockhirsch wieder fing (Randi capturou novamente o Bockhirsch), que tem as leituras restitutiva (pressupõe-se que o gato Bockhirsch estivera preso antes, mas isso não quer dizer que seu estado anterior de "prisioneiro" tenha sido produzido pelo mesmo Randi que o restituiu a tal estado) e repetitiva (pressupõe-se que o gato Bockhirsch fora capturado antes por Randi). Para dar conta das duas leituras em termos de escopo, Stechow propõe uma decomposição sintática do VP contendo o verbo fangen como acima, em que wieder pode modificar somente a parte da estrutura que veicula o estado representado por PRISONER, o constituinte encabeçado por $\mathrm{X}$ (leitura restitutiva), ou pode modificar a estrutura inteira, sendo anexado ao Voice-P (leitura repetitiva). 
Assim, será a altura de anexação do advérbio na estrutura da sentença (incluindo-se aí uma decomposição sintática do significado do verbo fangen) que indicará qual das duas leituras associadas a wieder está em jogo. A denotação de wieder será sempre a mesma.

Marantz (2007), também desenvolvendo um tipo de análise baseada em escopo, trata do prefixo re- em inglês, que tem, aparentemente como no português, somente a leitura restitutiva. No texto de Marantz, a discussão sobre o prefixo serve muito mais para argumentar em favor de propostas de representação sintática da estrutura argumental dos verbos, na qual: (1) sintagmas nominais/determinantes complementos de alguns verbos são interpretados como eventos incoativos, de mudança de estado; (2) raízes associadas a verbos funcionam como modificadores adverbiais de eventos; (3) sintagmas verbais com complemento em algum momento da derivação podem incluir mais de um evento, havendo uma relação causal entre ambos (HALE; KEYSER, 2002). O esquema abaixo indica como deve ser a estrutura do sintagma verbal na proposta de Marantz (2007):

\section{Esquema 2}

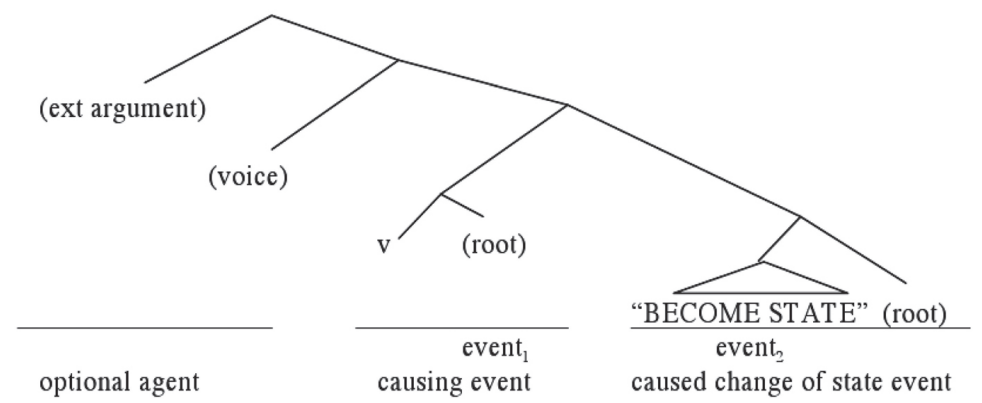

Fonte: Marantz (2007, p.3).

Os pontos indicados por (root) são os locais onde a raiz do verbo pode inserirse, modificando adverbialmente a estrutura. Em verbos inergativos, o final da estrutura, indicando o evento 2, está ausente, e a raiz se anexa diretamente ao v, modificando o evento (evento 1), introduzido por este morfema. Tipicamente, são verbos de atividade (rir, pular, gritar etc.), chamados por Marantz de monoeventivos (pois só há o evento 1), e o seu único argumento (externo) é inserido pelo núcleo Voz, nesse caso obrigatoriamente presente.

Já em verbos de alternância causativo-incoativa (abrir, ferver, rodar etc.), a raiz não está modificando o núcleo v, mas o evento 2, uma leitura do complemento (nesse caso obrigatório) do verbo. Isso quer dizer que o DP complemento sofre 
um type-shifting, sendo interpretado não como uma entidade, mas como um evento incoativo compatível com o verbo associado (com o significado da raiz que o modifica). O morfema verbalizador v também está presente na estrutura e introduz o evento 1, evento causador, não especificado (a raiz não se anexa a ele, como no caso anterior). Aqui, o núcleo de Voz é opcional: na alternante incoativa, está ausente; na causativa, está presente.

Quando o verbo é exclusivamente transitivo, e a interpretação do sintagma verbal encabeçado por ele inclui uma mudança de estado do complemento (um tipo de accomplishment encabeçado por verbos como: pintar, comer, fumar etc.), este complemento denota o evento 2 , mas a raiz não o modifica: como nos verbos monoeventivos, modifica o (se anexa diretamente ao) v, morfema que introduz o evento causador (evento 1). Como se anexa diretamente ao v, a presença do núcleo Voz, introduzindo o argumento externo, é obrigatória. ${ }^{3}$

Havendo dois eventos irmãos na estrutura, a relação entre eles é de causalidade, uma espécie de leitura default para tal configuração. (HALE; KEYSER, 1993, 2002). Portanto, o evento 1 causa o evento 2, sem a necessidade de haver um morfema causador que introduza esta relação. Além disso, a proposta evita a postulação de morfemas introdutores de operadores do tipo BECOME (como na proposta de Stechow acima), pois assume que o próprio DP complemento é interpretado como um evento incoativo causado. Tal interpretação, é importante dizê-lo, ocorre em configurações específicas para o DP.

Com exceção dos verbos monoeventivos, os outros tipos de verbos discutidos na proposta aceitam o prefixo re-. Para Marantz (2007), o prefixo re- modifica somente o evento 2. Como tais subeventos incoativos são, de fato, leituras dos DPs complementos dos verbos, re- seleciona, categorialmente, um sintagma determinante, e, semanticamente, um evento incoativo. Os esquemas a seguir explicitam a ideia:

3 A não ser que se assuma que os verbos (exclusivamente) inacusativos sejam, de fato, potencialmente alternantes, as propostas acima aparentemente não os contemplam. Também ficam de fora os verbos de estado, verbos psicológicos, verbos do tipo location-locatum, etc. 


\section{Esquema 3}

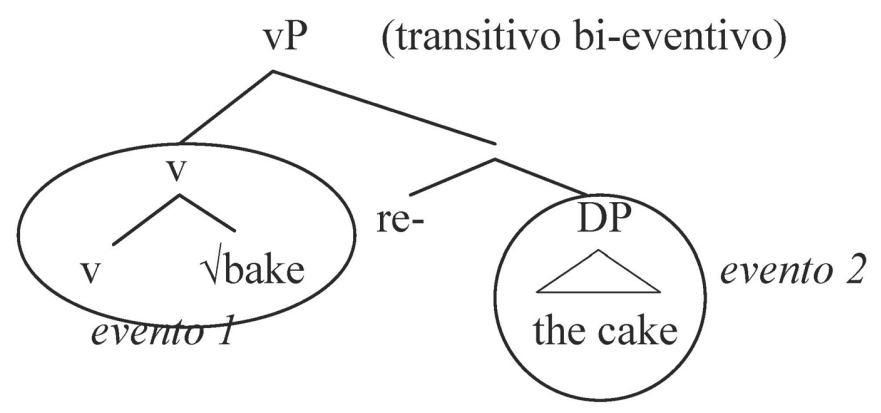

Fonte: Marantz (2006, p.12).

\section{Esquema 4}

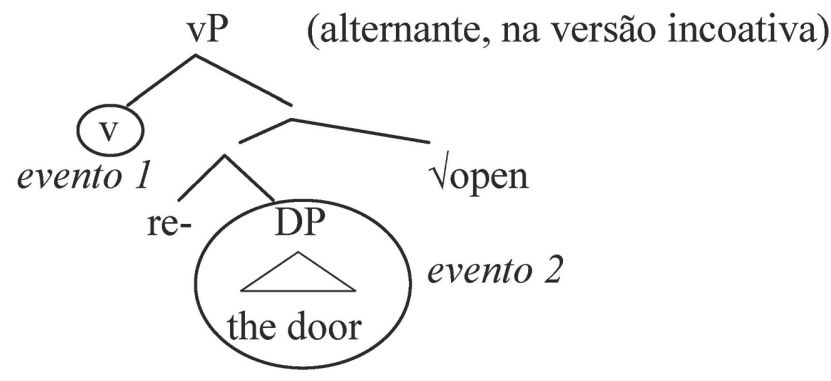

Fonte: Baseado em Marantz (2007).

Observe-se que no esquema 3 e no esquema 4 re- tem escopo restrito, tomando apenas o DP complemento (em alguma etapa da derivação) do verbo. Ora, uma vez que re- é restitutivo, isto é, repete um estado em que o referente do DP estava anteriormente, re- deveria ter escopo sobre a parte da estrutura que denota tal estado, como em Stechow (1996) (ver o esquema 1). Contudo, Marantz (2007) o observa, isso não acontece na proposta: quando repintamos o muro (repainted the wall), por exemplo, restituímos, segundo Marantz (2007), o muro ao estado "pintado"; ou seja, o estado atingido pelo subevento incoativo é denotado pela raiz do verbo paint, raiz anexada diretamente ao v como no esquema 3, fora do escopo do prefixo. No caso de reabrir, a raiz, que também introduz a denotação do estado, fica fora do escopo do prefixo. Como resolver o problema? 
Marantz (2007) propõe a seguinte saída (esboçada e não muito clara): re- tem escopo sobre o DP que denota mudança de estado, dentro da fase vP (CHOMSKY, 1999; MARANTZ, 2001), mas o estado atingido por essa mudança pode ser especificado, dentro da mesma fase, fora do escopo de re-. O argumento é que a interpretação do DP de mudança de estado envolve uma variável para o estado final, a ser preenchida pelo primeiro elemento relevante no que ele chama de "espinha de seleção do v" dentro da fase vP. Esse elemento é o modificador do $\mathrm{v}$ - a raiz do verbo.

Apesar das inúmeras virtudes que as abordagens acima apresentam, tanto a proposta de Stechow (1996) quanto a proposta de Marantz (2007) apresentam dificuldades importantes. O trabalho de Stechow, por exemplo, se baseia numa decomposição sintática do significado, em estrutura profunda, que inclui nós como o XP, cujo núcleo, X, é representado pela expressão PRISONER. De algum modo (por algum tipo de transformação), o núcleo X, o núcleo V, que alberga o operador BECOME, e o núcleo Voz se tornam, em estrutura de superfície, o verbo fangen. Evidentemente, algo mais do que "mover constituinte" entra em cena para transformar a estrutura do esquema $1 \mathrm{em}$ uma forma superficial que inclui o verbo em questão, aparentemente ausente na estrutura profunda da sentença.

Quanto à proposta de Marantz (2007), não me parece claro como garantimos que o prefixo re- não restitua o estado "vermelho" ao muro em sentenças como he repainted the wall red. Observe-se a estrutura a seguir proposta para construções resultativas tendo o verbo prefixado:

\section{Esquema 5}

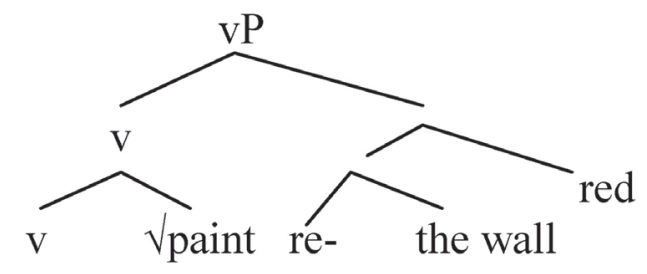

Fonte: Marantz (2007, p.17)

Ainda que não seja muito claro nem o que Marantz (2007) chama de "primeiro elemento relevante" nem o que chama de "espinha de seleção do v", o primeiro elemento, dentro do vP, a fornecer algo que preencha a variável para o estado decorrente do evento incoativo denotado pelo DP é o adjetivo red, não a raiz VPAINT. Mas não é o estado "vermelho" que é restituído (este deveria estar fora do escopo de re-), e sim, supostamente, um estado "pintado" denotado pela raiz. 
Ademais, a proposta de Marantz (2007) tem a estranha característica de adotar uma abordagem baseada na noção de escopo de operador (ainda que a semântica do prefixo não fique muito clara no texto), mas, ao mesmo tempo, afirmar que justamente o elemento que introduz o estado pressuposto está sempre fora do escopo do elemento que introduz a pressuposição na estrutura (ainda que ambos estejam dentro da mesma fase).

\section{A proposta deste artigo}

Como Stechow (1996), desenvolverei uma análise do prefixo re- no português baseada na noção de escopo sintático. Supondo ser possível decompor sintaticamente as estruturas de evento associadas aos verbos (RAMCHAND, 2008; MARANTZ, 2007; LIN, 2004; CUERVO, 2003; HALE; KEYSER, 2002; entre outros), proporei que o escopo do prefixo recai justamente sobre a parte desta representação sintática que inclui o estado atingido, mas não o evento ou o processo cuja culminação é o estado em questão.

No entanto, ainda que ambas tenham algumas semelhanças, as representações sintáticas das estruturas de eventos dos verbos aqui desenvolvidas não serão como as decomposições sintáticas dos significados dos verbos encontradas na análise de Stechow. As representações aqui propostas terão o espírito das desenvolvidas por vários autores, em particular as encontradas em Marantz (2007) e Hale e Keyser (2002). Isso quer dizer que a parte da estrutura de evento sintaticamente representada modificada pelo (no escopo do) prefixo re-pode conter: (1) uma raiz ou radical que denote um estado atingido; (2) um sintagma preposicional complemento que também denote um estado decorrente do evento descrito pelo verbo; (3) algum tipo de sintagma preposicional incorporado, como ocorre em algumas análises (HALE; KEYSER, 1993) para verbos do tipo location-locatum, que, do mesmo modo, denote um estado atingido; (4) uma predicação interna, estativa, criada por algum morfema associado ao verbo.

Tomemos como exemplo a sentença: o processo recurvou uma barra de alumínio.

Assumindo que em curvar a raiz descreve o estado alvo (PARSONS, 1990; KRATZER, 2000) do processo denotado pelo verbo (no esquema a seguir: $\mathrm{e}_{2}=$ "curvo") e que o morfema verbalizador introduz um subevento ( $\mathrm{e}_{1}$, não especificado) causador de tal estado (MARANTZ, 2007; HALE; KEYSER, 1993, 2002), a estrutura do sintagma verbal curv(ar) uma barra de alumínio deverá ser a seguinte: 


\section{Esquema 6}

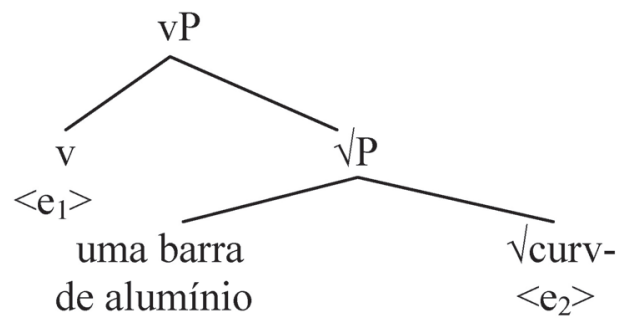

Fonte: Elaboração própria.

No esquema 6, acima, a raiz estabelece uma predicação para o complemento do verbo, o DP "uma barra de alumínio", e tal predicado denota o estado $e_{2}$, atingido pelo referente do DP em questão quando o processo culmina. No esquema 7, abaixo, o prefixo re- é adjungido ao sintagma raiz, modificando (repetindo) o estado denotado pela predicação. Re-introduz, na semântica verbal, a pressuposição do estado $e_{2}$, e o morfema v introduz o evento $e_{1}$ na estrutura, evento causador da reocorrência do estado $e_{2}$.

É importante notar que no esquema 7 re- tem escopo sobre o DP "uma barra de alumínio", o que cria problemas para o existential closure. As relações de escopo, como estão, deverão produzir a seguinte leitura: novamente existe uma barra de alumínio que atingiu o estado "curvo". Contudo, a leitura correta deveria ser: existe uma barra de alumínio que novamente atingiu o estado "curvo", na qual o operador existencial tem escopo sobre o operador introduzido pelo prefixo.

Uma maneira de conseguir a configuração adequada entre operadores que produza essa interpretação é mover o sintagma determinante para uma posição mais alta na estrutura. Essa configuração ocorre necessariamente, uma vez que o complemento deve mover-se para o especificador de vP para checar caso acusativo (CHOMSKY, 1995) ou valorar o traço EPP do vP (CHOMSKY, 1999). O esquema 8 o mostra. 


\section{Esquema 7}

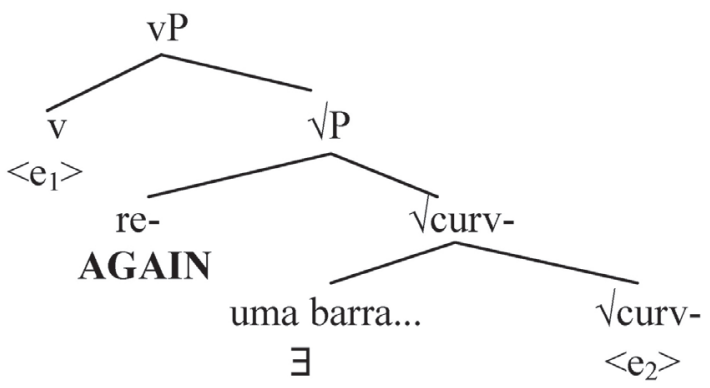

Fonte: Elaboração própria.

\section{Esquema 8}

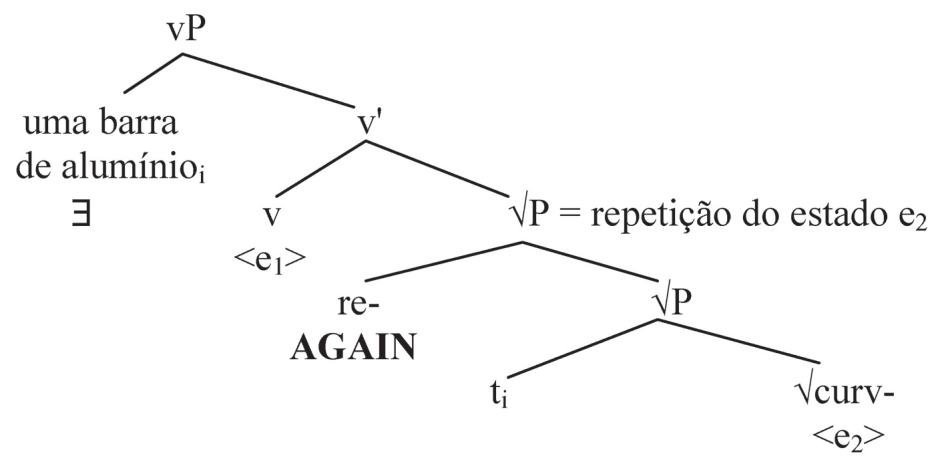

Fonte: Elaboração própria.

À estrutura acima pode ser anexado um núcleo Voz (KRATZER, 1996), que abre uma posição para o argumento externo e lhe atribui um papel, temático ou aspectual (agente, originador etc.). A operação semântica identificação de evento (KRATZER, 1996) identifica os eventos introduzidos pelo morfema v e pelo morfema Voz, o que faz com que o ocupante da posição de especificador do núcleo Voz (no exemplo, o DP "o Cláudio") seja interpretado como o originador ou o agente do evento que causa o estado "curvo", introduzido pela raiz. A representação arbórea abaixo o explicita, omitindo os movimentos de núcleo (que ocorrem no caminho para a interface fonológica, na estrutura morfológica) (MARVIN, 2002) necessários à formação morfológica do verbo: 


\section{Esquema 9}

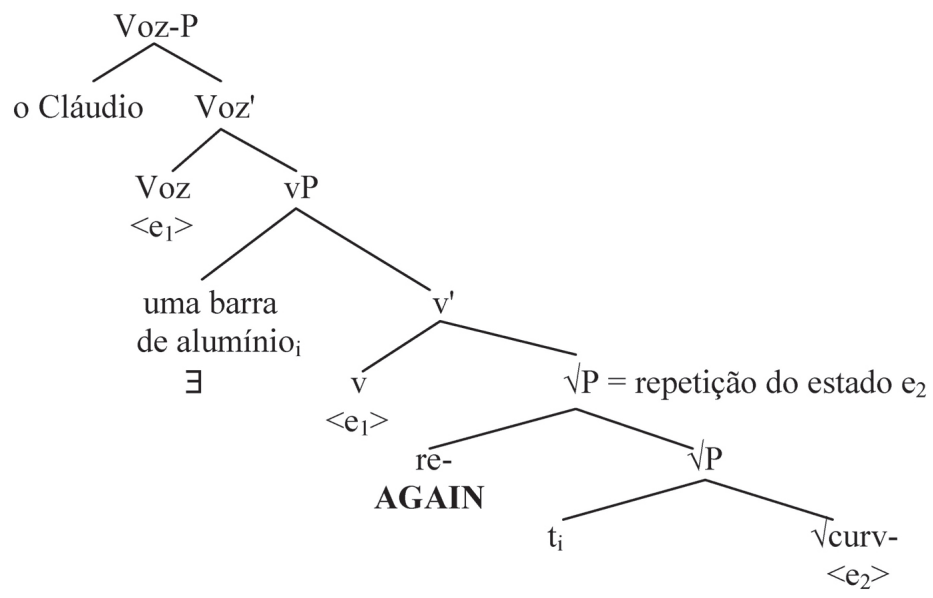

Fonte: Elaboração própria.

Observe-se que no esquema 6 as interpretações atribuídas a seus componentes não diferem muito do que é proposto em Marantz (2007) para verbos de alternância causativo-incoativa. Uma vez que estamos adotando algumas ideias de Marantz sobre a estrutura dos vPs, a questão que se coloca agora é como lidar com casos como o de pintar ou assar, cujas raízes, em sua proposta (esquema 3), denotam modos para atividade e são diretamente anexadas ao v, como modificadores, ficando, assim, fora do escopo do prefixo.

Como vimos acima, Marantz apresenta uma solução para a questão do escopo, assumindo que a raiz de pintar fornece o estado atingido pela mudança de estado denotada pelo DP. A solução, contudo, apresenta um problema importante. Tomemos a seguinte situação: o tronco de uma árvore do meu quintal descascou em alguns pontos e sua cor ficou irregular; para que a cor do tronco fique homogênea, resolvo repintá-lo com uma cor próxima à das partes mais escuras. Ora, se, como afirma Marantz, o estado restituído é denotado pela raiz do verbo, então, para que repintar pudesse ser usado no contexto acima, a raiz deveria poder denotar um estado que não implicasse o processo de pintar, como ocorre com a raiz do verbo abrir, por exemplo. Portanto, poderíamos formar passivas adjetivas que denotassem tal estado, um estado que não necessariamente decorreria do evento associado ao verbo (passivas adjetivas de estado alvo, nos termos de KRATZER, 2000; ou derivadas diretamente da raiz, como em EMBICK, 2004 e MARANTZ, 2007). Sabemos, entretanto, que isso não é verdade: sentenças como "o muro está pintado" ou "o muro pintado daquela praça caiu" implicam que o muro tenha sido pintado (houve o evento de pintá-lo) em algum momento do passado, antes da emissão da sentença. Observe-se que a mesma implicação não ocorre em "a 
caverna aberta para oeste tem pinturas rupestres"; aqui, não necessariamente houve o evento de abrir a caverna antes da emissão da sentença. Isso porque a raiz do verbo abrir parece denotar não um modo de agir (como ocorre com o verbo pintar) ou um processo, mas um estado do complemento do verbo, estado que normalmente decorre de um evento, mas não necessariamente .

Uma solução possível para o problema, mais compatível com nossos pressupostos, é dizer que o verbo pintar, quando transitivo, é bimorfêmico, com um morfema nulo que introduz um estado (alvo) e cria uma predicação para o complemento, como no esquema 10. Como nos casos anteriores, havendo duas eventualidades na estrutura (o evento introduzido por v e o estado introduzido por X), a leitura default é de "causação" (HALE; KEYSER, 1993, 2002; MARANTZ, 2006, 2007) entre elas: evento causa estado; e o estado introduzido por X será compatível com o conteúdo enciclopédico veiculado pela raiz na fase em que ambos ocorrem (o vP). Sendo assim, a raiz de pintar continua denotando um modo (não um estado), anexando-se diretamente a v, e re- se adjungiria à predicação criada pelo morfema nulo, como no esquema 11:

\section{Esquema 10}

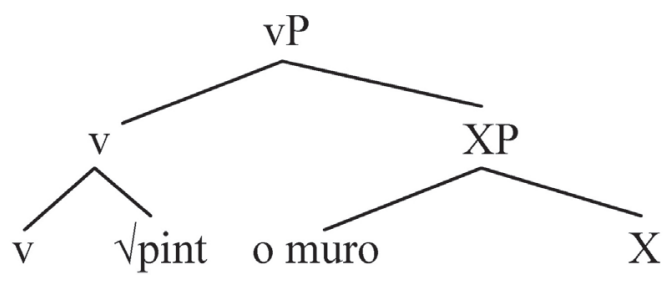

Fonte: Elaboração própria.

\section{Esquema 11}

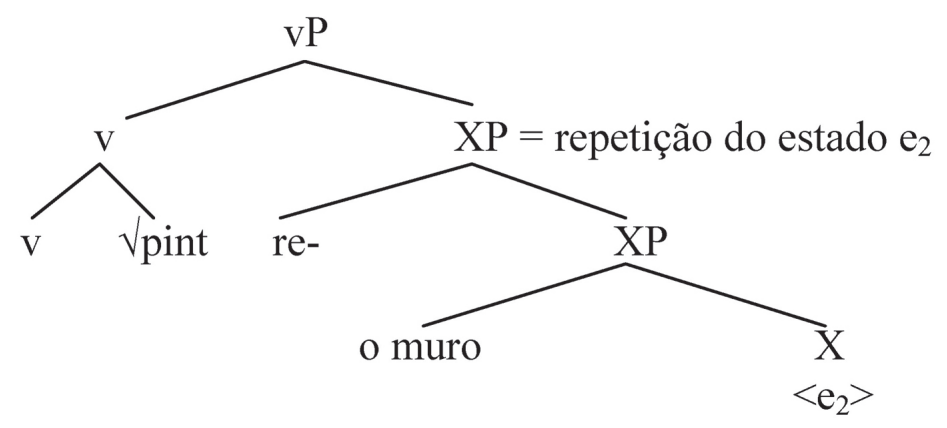

Fonte: Elaboração própria. 
A estrutura do esquema 10 se baseia em proposta de Marantz (2006) para verbos bi-morfêmicos como construir, destruir ou instruir. Nesses verbos, o morfema X do esquema 10 é, na verdade, um dos prefixos con-, des- e in-. A diferença é que, enquanto a raiz $\sqrt{S T R U}$ - de tais verbos só ocorre em uma estrutura como a do esquema 10, raízes como $\sqrt{ }$ PINT- de pintar talvez ocorram também em estruturas monoeventivas, como a representada a seguir. Isso explicaria não só o fato de tais verbos ocorrerem sem complementos ("João pinta plantando bananeira"; "esse forno assa a altas temperaturas"), mas também o fato de usos intransitivos de pintar e assar não aceitarem o prefixo, uma vez que re- toma justamente a predicação introduzida por X ( ${ }^{*}$ João repinta plantando bananeira; *esse forno reassa a altas temperaturas):

\section{Esquema 12}

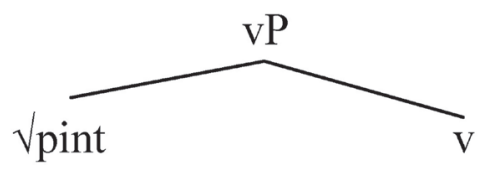

Fonte: Elaboração própria.

A proposta representada no esquema 10 não sofre de nenhum dos males das propostas que assumem que a raiz $\sqrt{ }$ PINT- pode denotar um estado. Por exemplo, se o morfema X denota um estado que será um típico estado alvo (PARSONS, 1990; KRATZER, 2000) do evento causador, então XP denotará algo como "muro com uma determinada cor", não necessariamente "muro pintado", e seu uso no contexto discutido acima não será anômalo. A proposta do esquema 10 tampouco encerra a dificuldade fundamental da proposta de Stechow (1996), apontada na seção anterior.

Observe-se que a posição de re- nas estruturas acima permite explicar naturalmente por que o prefixo não tem escopo sobre advérbios modificadores de processos: tais advérbios são ajungidos ou ao vP ou ao Voz-P, ficando, assim, fora do escopo do prefixo.

As representações das estruturas de argumentos aqui apresentadas assumem um caráter parcialmente marcado por uma visão neodavidsoniana da semântica dos verbos, à maneira de Parsons (1990), mas com estruturas sintáticas representando as subeventualidades, não simplesmente a decomposição semântica proposta por Parsons, além de papéis aspectuais atribuídos aos argumentos, não temáticos. (TENNY, 1994; BORER, 2005; RAMCHAND, 2008). 


\section{Semântica e seleção do prefixo}

Assumirei que o prefixo faz seleção semântica somente (MEDEIROS, 2010). Isto é, ele poderá combinar-se, na sintaxe, através de algum tipo de merge, com elementos de qualquer natureza categorial (raízes, morfemas, preposições etc.), mas, quando a derivação sintática chegar à interface com os sistemas de interpretação semântica, o constituinte ao qual o prefixo se anexa deverá ser de um determinado tipo semântico, compatível com o tipo semântico do prefixo, para que a derivação convirja nessa interface. Assumo que, em alguns casos muito especiais, a presença do prefixo pode forçar uma interpretação estativa (mudança de tipo) da parte da estrutura sobre a qual ele tem escopo dentro da fase vP.

Na proposta, todos os elementos modificados criam uma predicação e denotam estados; o prefixo se adjunge a eles, modifica-os, mas devolve algo do mesmo tipo semântico, que fará parte do sintagma verbal. Ora, assumindo que o tipo semântico do elemento predicador é $\langle\mathrm{e},<\mathrm{S}, \mathrm{t}\rangle>$, isto é, que denota uma função que mapeia uma entidade em uma função que mapeia uma eventualidade num valor verdade, então o prefixo deverá ter o seguinte tipo semântico, adequado às configurações apresentadas acima: $<<\mathrm{s}, \mathrm{t}\rangle,<\mathrm{s}, \mathrm{t}>>$.

Proponho, preliminarmente, que a definição semântica de re- seja:

\section{Esquema 13 \\ $\lambda \mathrm{f}_{<\mathrm{s}, \mathrm{t}>} \cdot \lambda \mathrm{s}_{\mathrm{s}} \cdot[[\mathrm{AGAIN}]] \mathrm{f}\left(\mathrm{s}_{\mathrm{s}}\right)$}

Fonte: Elaboração própria.

O operador AGAIN introduzirá a pressuposição na estrutura, tomando um estado (a variável s). Não basta, entretanto, uma ocorrência anterior do estado para caracterizar as condições de verdade veiculadas pelo operador; é necessário que a reocorrência do estado parta de uma situação em que o estado a ser repetido não mais esteja valendo na ocasião de sua repetição. Assim, por exemplo, para que o prefixo re- seja usado adequadamente na situação descrita pelo esquema 8, é preciso não só que a barra tenha estado curva antes do seu recurvamento, mas que não mais esteja curva quando do seu recurvamento.

Parte do cálculo da estrutura do esquema 8 seria algo como: 


\section{Esquema 14}

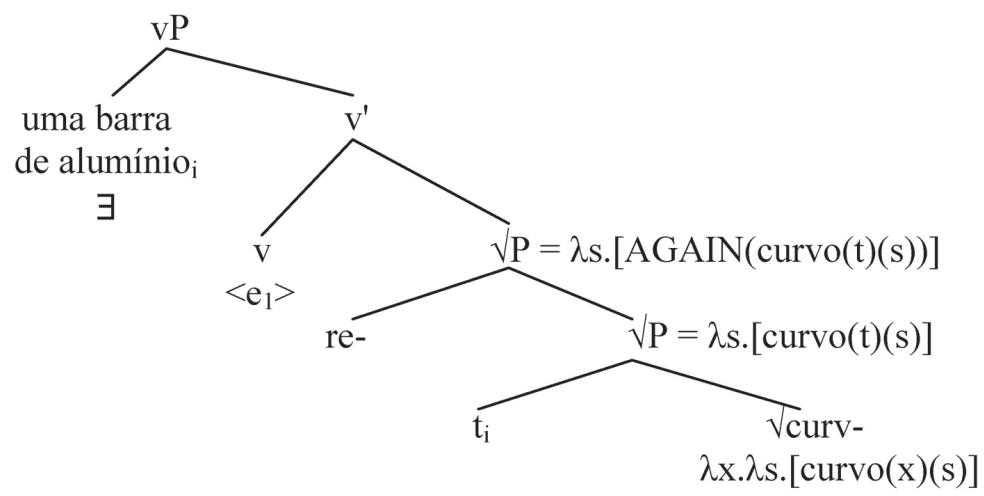

Fonte: Elaboração própria.

No nó vP, teremos a seguinte denotação: existe uma barra de alumínio $x$ tal que um evento e não determinado (introduzido por v) causa a repetição (re-) do estado $S$ "curvo" em $X$.

No caso de vPs que incluem uma raiz anexada diretamente ao v (como pintar), a semântica do morfema X variará de acordo com a raiz e com o DP presentes no vP. Uma vez que, de fato, todo o cálculo ocorrerá após o fechamento da fase (CHOMSKY, 1999; MARANTZ, 2001), a semântica do elemento X poderá levar em conta o que há no ambiente sintático estabelecido na fase, incluindo-se aí tanto o complemento do verbo como a raiz envolvida.

\section{A morfologia dos verbos com prefixo re-}

A forma fonológica das palavras depende de movimentos de núcleo que ocorrem pós-sintaticamente, na estrutura morfológica. (HALE; MARANTZ, 1993; HARLEY; NOYER, 1999; MARVIN, 2002). Esses movimentos desfazem as configurações em que as relações de escopo se dão; mas, como ocorrem no caminho para a forma fonológica da arquitetura da gramática, não no caminho para a forma lógica (e a leitura semântica), o fato de desfazerem tais configurações não cria problemas para a interpretação da sentença. Contudo, é necessário que certos arranjos hierárquicos se verifiquem entre os morfemas, para que a interface fonológica identifique, quando da formação das "palavras" (morfofonológicas), que morfemas estão mais próximos da raiz e quais mais distantes.

Nos verbos em que a raiz predica, como no esquema 8 acima, não há problema. A formação se dá como apresentada nos esquemas 15 e 16. Em todos os esquemas 
a seguir, $t_{i}$ é o vestígio do complemento, que se moveu para especificador de vP para checar Caso acusativo ou valorar EPP de v (ver discussão acima).

\section{Esquema 15}

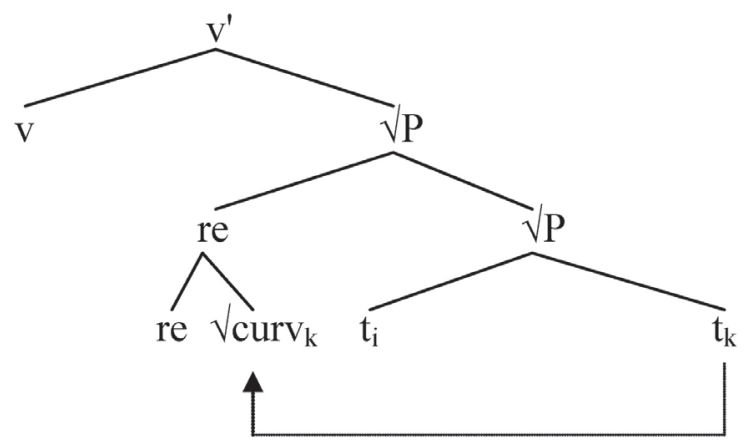

Fonte: Elaboração própria.

\section{Esquema 16}

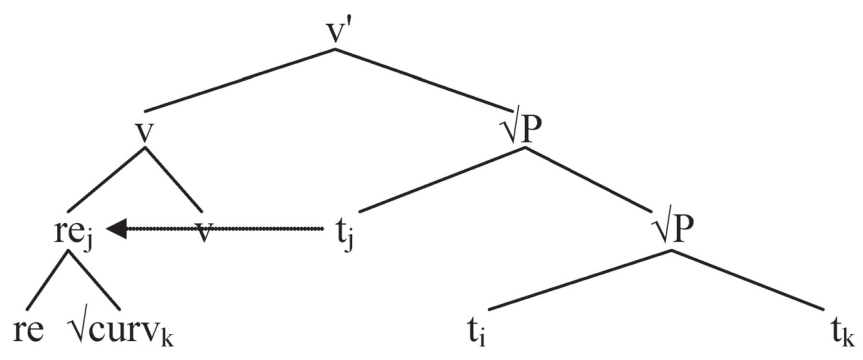

Fonte: Elaboração própria.

Já nos verbos em que a raiz se anexa diretamente ao v, como no esquema 11, não é muito claro como os movimentos de núcleo criarão a configuração adequada, na qual $\mathrm{X}$, que deveria ser um prefixo como con-em construir, fica mais próximo da raiz do que o prefixo re-. Uma possibilidade é a apresentada a seguir, na qual o sintagma re- se adjunge a $\mathrm{v}$ e a raiz move-se para adjungir-se ao nó terminal X na estrutura, como os esquemas a seguir ilustram: 


\section{Esquema 17}

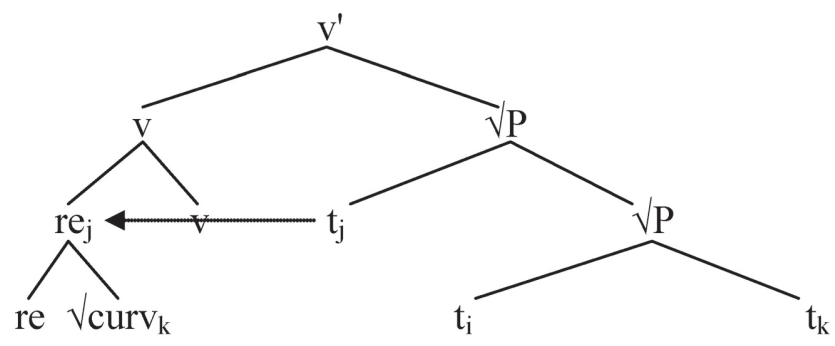

Fonte: Elaboração própria.

\section{Esquema 18}

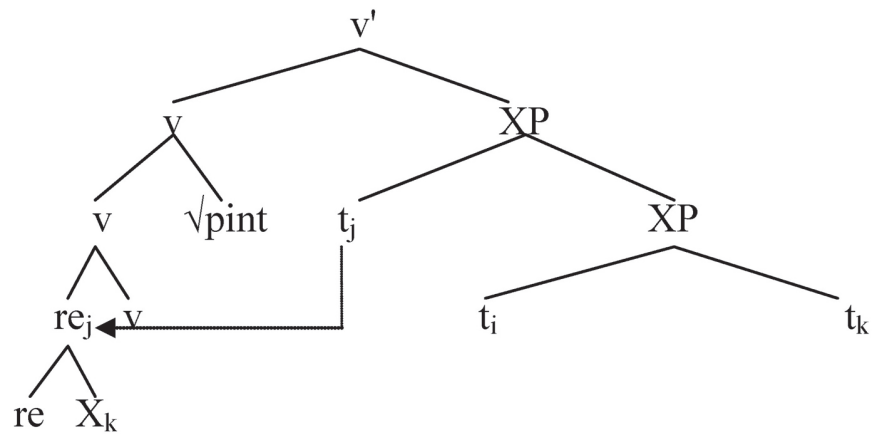

Fonte: Elaboração própria.

\section{Esquema 19}

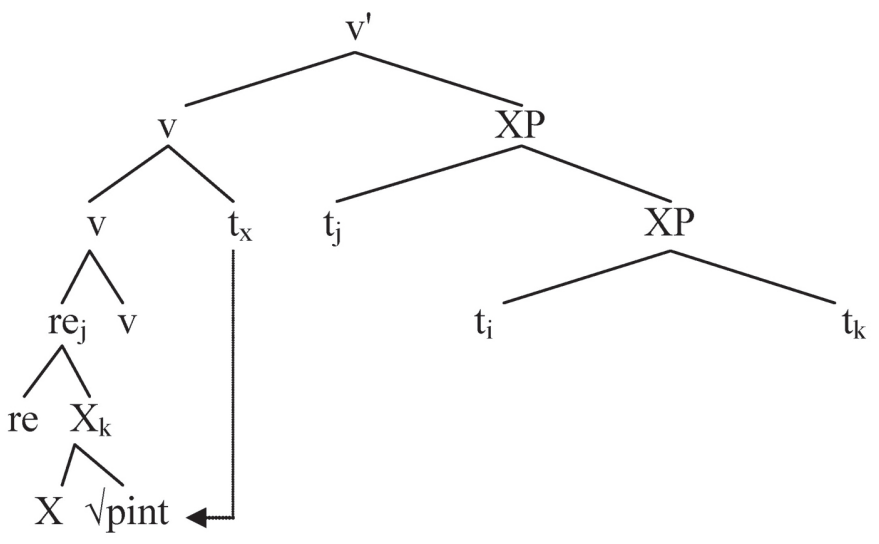

Fonte: Elaboração própria. 
Observe-se que em todos os casos o sintagma re- (que é composto pelo prefixo e outro morfema adjunto, podendo este ser uma raiz ou mesmo um constituinte mais complexo) se move adjungindo-se diretamente a v. É justamente pelo fato de os constituintes encabeçados por prefixos adjungirem-se sempre, na proposta, ao verbalizador, que a configuração adequada é possível: se, no esquema 17, o alvo do movimento do constituinte em questão fosse a raiz (um dos pousos possíveis para o movimento), X não seria o morfema mais próximo da raiz, como deveria ser.

A proposta, entretanto, encerra pelo menos uma dificuldade: não apresenta uma razão clara para o movimento que a raiz faz em (19). Como se vê na estrutura, temos três pousos possíveis para a adjunção da raiz; no entanto, ela deve adjungir-se ao morfema mais baixo na estrutura (o morfema X em [19]), jamais a qualquer um dos outros. Deixo uma investigação sobre as possíveis razões desse movimento para trabalhos futuros. Observe-se, contudo, que, na estrutura, $\mathrm{X}$, antes da anexação da raiz, é o único nó ao qual nenhum outro morfema se adjungiu.

\section{Algumas consequências das generalizações e propostas acima}

\section{(a) Verbos de alternância}

Vimos que o licenciamento do prefixo está associado à existência de um estado que tipicamente marca a culminação do evento descrito pelo verbo (arrisco-me a dizer que se trata de um típico estado alvo de tal evento, conforme definição de Parsons (1990); vimos, também, que verbos inacusativos e de alternância causativo-incoativa com esta característica aceitam o prefixo (por exemplo, o esquema 8). Observe-se, contudo, que a generalização acima também nos leva a concluir que verbos inacusativos ou de alternância cuja semântica não inclua um estado atingido tipicamente não aceitem a prefixação ou a aceitem marginalmente, em contextos bastante específicos. A previsão se confirma; temos reabrir, refechar, reexistir, reacordar, renascer, recozinhar, reafundar, referver, reesquentar, recolar, reesfriar, recongelar, regelar etc. Mas não, ou marginalmente, ?reescorrer, ??reescorregar, ${ }^{*}$ redeslizar, ${ }^{*}$ regirar, ${ }^{*}$ rerrodar, ${ }^{*}$ rerrolar, ${ }^{*}$ recrescer etc.

Com isso, fica claro que não basta haver uma subeventualidade codificada de alguma forma no verbo: essa subeventualidade não pode ser dinâmica.

\section{(b) Verbos psicológicos do tipo objeto experienciador}

Ainda seguindo o raciocínio acima sobre o que condiciona a prefixação, esperaríamos que verbos do tipo objeto experienciador aceitassem o prefixo, já que os processos que tais verbos descrevem envolvem um determinado estado alcançado por seus complementos. A expectativa se confirma; mesmo que 
alguns dos exemplos a seguir sejam um tanto incomuns, a prefixação aqui é bem mais aceitável que na maioria dos verbos que só incluem eventos dinâmicos em sua denotação: reacabrunhar, reagoniar, reanestesiar, reangustiar, reanimar, reapavorar, rearrasar, rearrepiar, reatemorizar, reaterrorizar, reazucrinar, recativar, ?recontrariar, recomover, reconvencer, ?redeprimir, redesnortear, reeletrizar, reembriagar, reemocionar, reempolgar, reenervar, reentorpecer, reestressar, reestafar, reestimular, reestontear, reexcitar, reimpressionar, reincomodar, reinebriar, reinquietar, reintimidar, ?reirritar, reoprimir, ressensibilizar etc.

\section{(c) Verbos bitransitivos}

Também poderíamos esperar que alguns verbos bitransitivos, quando seus significados incluem um estado atingido pelo complemento direto, aceitem o prefixo. Por exemplo, nos verbos colocar e pôr, a preposição locativa em, que introduz o objeto indireto do verbo, aparentemente indica um estado do objeto direto: " $x$ em $y$ ". Uma explicação possível, baseada na preliminar representação do esquema 20, seria a seguinte: os dois argumentos internos são relacionados por uma preposição (PESETSKY, 1995; entre outros), que, aqui, estabelecerá um estado do complemento direto do verbo: "livro na mesa". Re- terá escopo sobre este constituinte (um PP), como o esquema 20 o mostra:

(4) Marcelo repôs o livro na mesa.

\section{Esquema 20}

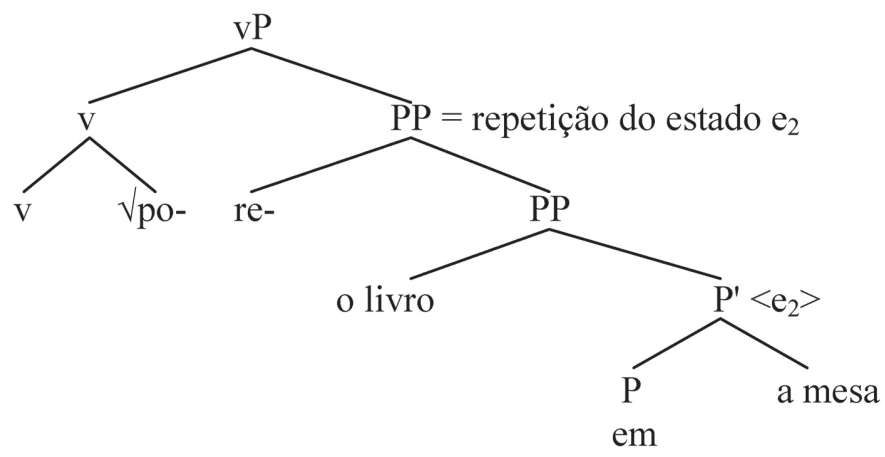

Fonte: Elaboração própria.

Já verbos bitransitivos que selecionam as preposições a ou para, como dar, levar, doar, enviar, apresentar etc., não têm um comportamento homogêneo em relação ao licenciamento do prefixo. Vejam-se os exemplos: 
(5) *Marcelo redeu/ ${ }^{*}$ relevou/??redoou o livro para/a Maria.

(6) Marcelo reenviou a carta para Maria/reapresentou Marcelo para/a Maria.

Uma explicação possível, compatível com o que vimos assumindo até aqui, é que tais preposições (a e para) são ambíguas por apontarem para o resultado de um movimento, de um local atingido, de um estado em que $X$, objeto direto, está em $y$, objeto indireto, ou por descreverem um direcionamento para um evento dinâmico, um deslocamento no espaço com um determinado alvo. Assim, na fase vP, verbos como dar, doar, levar (a presença de suas raízes dentro da fase) forçam a interpretação de "direcionamento de evento dinâmico" para a preposição, fazendo com que o PP no esquema 20 seja interpretado como um deslocamento no espaço, incompatível com a prefixação; já verbos como apresentar ou enviar (suas raízes, presentes na fase vP) forçam uma interpretação focada no estado alcançado pela denotação do complemento direto $(x$ em $y)$, resultado de um deslocamento, interpretação compatível com a prefixação.

As estruturas de todos os verbos mencionados nesta subseção são, a princípio, como a representada no esquema 20 acima.

Para terminar essa discussão, observe-se que uma mudança na interpretação dos complementos de um verbo faz com que tal verbo deixe de licenciar o prefixo. No caso de pôr, por exemplo, se o complemento direto atingir um estado no final do processo, como no exemplo (5), então o prefixo é licenciado; se não for esse o caso, como em Pedro pôs o bandido para correr, a prefixação não é mais aceitável: *Pedro repôs o bandido para correr.

\section{(d) Interação com outros prefixos}

Se o prefixo toma um estado e devolve um estado, e a única restrição sobre ele é que tome estados em seu escopo, então se espera que seja possível que um verbo seja prefixado mais de uma vez com re-, o que se verifica:

(7) "Ainda sinto que a rerreconstrução do Haiti, após o terremoto, por que 2x re, a primeira re estava em andamento, quando veio a catástrofe [...]"4

Em Medeiros (2010), proponho que o prefixo des-nega um estado alvo incluído na denotação dos predicados em que ocorre. E que o tipo semântico do prefixo des- é $\langle<\mathrm{s}, \mathrm{t}\rangle,<\mathrm{s}, \mathrm{t}>>$, o mesmo tipo semântico proposto para o prefixo re- neste artigo. Isso quer dizer que os dois prefixos tomam estados e devolvem estados. Ora, se tomam os mesmos tipos de subeventualidades e não mudam a natureza delas,

4 Ver: <http://veja.abril.com.br/blog/reinaldo/geral/veja-1-carta-ao-leitor-o-melhor-e-o-pior-do-homem>. 
espera-se que seja possível aplicar-se re- sobre des- e vice-versa. Os exemplos a seguir, encontrados no Google, mostram-no:

(8) a. “(...) apenas a psicanálise reconhece esse nó de servidão imaginária que o amor sempre tem que redesfazer ou deslindar"s.

b. "Uma forma de desrefazer e destransformar que não cabe, portanto, em quaisquer outras formas das quais eu me pudesse ter lembrado, antes"'.

(9) a. "A proposta dos antropófagos era redesconstruir o Brasil, olhando para sua (....) necessidade de repensar e redesconstruir as práticas educativas em que não (...)"7

b. "Mia Couto firmou-se através de uma (...) deslumbrante arte de 'desreconstruir' a palavra, o fraseado, a língua comum."8

(10) a. "(...) o incansável exercício de inventar e sobrepor palavras, organizar sentimentos; criar, recriar e desrecriar cenas."

b. "Redescriação do Triatoma Oliveirai (Neiva, Pinto e Lent, 1939) Com Estudo da genitália externa de ambos os sexos (Heteróptera Reduviidae..."10

Outra previsão, ainda que menos direta, seria que, já que re- teoricamente ocorre nos mesmos contextos em que des- ocorre, espraríamos que, assim como des- participa do que a gramática tradicional chama de derivação parassintética (desossar, descascar), re- também deverá ocorrer em tais situações. Os exemplos que encontrei foram poucos, entretanto, existem. Também parece acontecer que, prefixando com re-, certas formas denominais aparentemente possíveis, mas não encontradas no vocabulário, se tornam um pouco mais aceitáveis que as formas não prefixadas ${ }^{11}$. Dois exemplos a seguir:

(11) a. desflorestar/reflorestar/*?florestar

b. desossar/?reossar/*?ossar

\footnotetext{
$5 \quad$ Ver:<www.estadosgerais.org/.../62-sem_ou_cem.shtml>.

6 Ver: $<$ saiadebalao.wordpress.com/2008/10/>.

7 Ver: <coralx.ufsm.br/tede/tde_busca/arquivo.php?codArquivo=2966>.

8 Ver: <cultura.portaldomovimento.com/novos_livros.html>.

9 Ver: <efranbueno.blog.uol.com.br/arch2010-08-29_2010-09-04.html>.

10 Ver: <http://www.estantevirtual.com.br/riodeletras/Sociedade-Brasileira-de-Entomologia-Revista-Brasileirade-Entomologia-Vol-40009713>.

11 Em Medeiros (2010) proponho que formas como ossar e cascar não são agramaticais ou impossíveis. Apenas raramente encontram condições de uso adequadas. Mas a sintaxe as gera.
} 


\section{Problemas das propostas}

O primeiro problema que se coloca é: verbos como ler ou empurrar aceitam o prefixo, como mostram os exemplos a seguir:

\section{(12) Cláudio releu o livro/reempurrou o carrinho.}

Mas a semântica dos predicados que envolvem esses verbos inclui um estado (alvo) atingido pelo seu complemento? Quando leio um livro, o livro fica "lido"; quando empurro um carrinho, o carrinho fica "empurrado"12?

No caso de empurrar, podemos imaginar que há um estado pressuposto, o local prévio onde o carrinho estava e para o qual foi reempurrado. Parece claro que re- não ocorrerá com empurrar em contextos nos quais não se pressuponha tal coisa. Exemplos como * João reempurra com grande habilidade ou ?? João reempurra carrinhos no supermercado ${ }^{13}$ são agramaticais ou bastante marginais. Possivelmente, em (12) temos uma elipse de um sintagma preposicional que indica o ponto final da atividade de empurrá-lo, sobre o qual o prefixo tem escopo.

Já no caso de reler, é possível que haja algum tipo de conceptualização na qual, após a leitura, o livro em (12) passe a ser, também, uma entidade da vida mental do leitor, uma representação ou interpretação nova do livro. Nesse sentido, o verbo ler produz algum tipo de mudança de estado no seu complemento. Ler, portanto, seria, do ponto de vista estrutural, um verbo como pintar, cuja raiz se anexa diretamente a v, e que, quando transitivo (porque há sentenças como "João lê muito bem", sem complemento), envolve um morfema como X acima (esquema 11). Talvez a mesma explicação valha para relembrar e rememorar.

A resposta definitiva, contudo, requer mais investigação.

Outro problema relevante está relacionado com a existência do morfema X em estruturas nas quais a raiz funciona como modificadora do evento causador. Seria X um núcleo funcional? Se sim, seu conteúdo deveria depender somente dos traços por ele albergados; não deveria depender do conteúdo enciclopédico da raiz presente na mesma fase em que ele ocorre. Mas esse não parece ser o caso: o conteúdo de X, com exceção talvez de denotar um evento ou estado, é essencialmente enciclopédico e contextualmente determinado, como ocorre com as raízes na Morfologia Distribuída. Outra saída seria considerar X como

12 Aqui, me refiro não ao que Parsons (1990) chama de leitura de "estado resultante", mas à leitura que ele chama de "estado alvo".

13 Mais aceitável talvez porque possa ser interpretado como "reempurrar carrinhos para o local onde ficam a disposição dos fregueses". É comum haver pessoas nos estacionamentos dos supermercados que recolhem carrinhos de compras abandonados pelos clientes em locais que dificultam a circulação dos veículos. Então, João acima tem a função de recolher tais carrinhos e reempurrá-los para o local onde devem ficar para que os clientes os tomem e os usem assim que chegarem ao supermercado. 
parte da raiz ou uma raiz independente, que se arranja sintaticamente com os outros constituintes. Entretanto, penso que supor que o elemento X é parte da raiz criaria problemas para as versões intransitivas dos verbos em questão, onde o X não deve ocorrer (segundo a proposta aqui apresentada); e supor que X é uma raiz entra em conflito com outros pressupostos da teoria, uma vez que $\mathrm{X}$ não precisa ter conteúdo fonológico e não seria um signo saussureano no sentido que Marantz (1999) dá ao termo. Há ainda a possibilidade de se tratarem tais prefixos como se fossem preposições incorporadas, mas que introduzem eventos na estrutura, e que ganham significado idiossincrático no contexto da fase vP. De todas as possibilidades, essa me parece ser a melhor, em particular porque, de fato, os prefixos de construir, instruir etc., são, pelo menos historicamente, oriundos de preposições. Contudo, seria necessário encontrar, mesmo considerando as possíveis idiossincrasias de significado permitidas na fase vP, uma contribuição (ou contribuições) mais ou menos constante(s) dos morfemas X nas estruturas em que ocorrem, e essa contribuição (ou contribuições) deveria(m) ser compatível(eis) com as contribuições de algumas das preposições do inventário da língua. Uma pesquisa dessa natureza, contudo, fica fora do escopo do presente artigo.

O estatuto de X dentro da teoria, portanto, ainda é indefinido, mas o manterei na proposta, pois resolve os problemas aqui discutidos. De fato, como o leitor deve ter percebido, os problemas de X são os mesmos que encontramos nas propostas de Marantz (2007) (entre outros autores) para os prefixos de verbos como construir, destruir, obstruir etc.

\section{Conclusão}

O presente artigo se propõe a entender a distribuição e a contribuição semântica do prefixo re- nos contextos em que ocorre. Vimos que: (a) de modo geral, o prefixo ocorre em predicados que incluam um estado decorrente de um evento, também incluído na denotação do predicado; (b) o prefixo repete o estado causado denotado pela predicação; (c) o estado pode ser veiculado por uma variedade de estruturas sintáticas. Para dar conta da variedade de situações em que ocorre, assumi, aqui, que o prefixo não faz seleção categorial, podendo modificar tanto raízes como sintagmas preposicionais, desde que os mesmos denotem estados (decorrentes de eventos). A consequência é que o prefixo terá escopo sintático sobre a parte da estrutura de eventos sintaticamente representada que veicula o estado em questão. Essa parte pode não conter o verbo ou sua raiz.

Mas, mais do que simplesmente descrever propriedades de um prefixo, o artigo aborda algumas questões de estrutura argumental, mostrando que uma representação sintática das estruturas de evento dos predicados apresenta vantagens em relação a abordagens tradicionais que levam em conta papéis 
temáticos atribuídos por um item lexical. Afinal, se abro uma porta ou rodo um pião, tanto o pião quanto a porta são pacientes (ou temas) dos respectivos verbos. No entanto, a aplicação do prefixo no primeiro caso (com o verbo abrir) é aceitável, mas, no segundo (com o verbo rodar), é, na melhor das hipóteses, bastante marginal. Ou seja, a teoria temática nada teria a dizer a respeito da distribuição de tal prefixo; sequer nos permitiria entender o que ele de fato denota. O mesmo não se pode dizer de uma abordagem baseada numa decomposição dos predicados em estruturas de evento, como a proposta neste artigo - que, ademais, permite tratar as questões relativas à interpretação do prefixo por meio de escopo sintático.

MEDEIROS, A. B. de. Remarks on prefix re-. Alfa, São Paulo, v.56, n.2, p.583-610, 2012.

- ABSTRACT: This work investigates the morphosyntactic, morphological and semantic properties of Brazilian Portuguese prefix re- in the framework of Distributed Morphology. It seeks to establish its distribution and semantic contribution on the contexts in which they occur. This article shows evidences that the prefix studied here modifies (repeats) states that may be the target of the event described by the verb in which it is licensed. Assuming event structures syntactically represented, we understand the distribution of the prefix and explain the interpretation of the prefixed verb in terms of scope of the prefix in the event structure associated to the base verb: in the proposal, the prefix will scope the part of the event strucutre which denotes the target state. And we do not find the prefix in verbs which are not associated to event structures that include a state in their denotation. Once states in event structures may be denoted by adjectives, bare roots, some kinds of prepositional phrases, etc., we argue that the prefix does not make a categorial selection.

- KEYWORDS: Prefix re-. Distributed morphology. Event structure.

\section{REFERÊNCIAS}

BORER, H. Structuring sense. Oxford: Oxford University Press, 2005.

CHOMSKY, N. Derivation by phase. Cambridge: MIT, 1999. Não publicado. The minimalist program. Cambridge: MIT Press, 1995.

CUERVO, M. C. Datives at large. 2003. 211f. Thesis (Doctor of Linguistics) - MIT, Cambridge, 2003.

DOWTY, D. Word meaning and montague grammar. Reidel: Dodrecht, 1979.

EMBICK, D. On the structure of resultative participles in English. Linguistic Inquiry, Cambridge, n.35, v.3, p.335-392, 2004.

HALE, K.; KEYSER, S. J. On argument structure and the lexical expression of syntactic relations. In: HALE, K; KEYSER, S. J. (Ed.). The view from building 20. Cambridge: MIT Press, 1993. p.53-109. 
. Prolegomenon to a theory of argument structure. Cambridge: MIT Press, 2002.

HALE, K.; MARANTZ, A. Distributed morphology and the pieces of inflection. In: HALE, K.; KEYSER, S. (Ed.). The view from building 20. Cambridge: MIT Press, 1993. p.111-176.

HARLEY,H; NOYER, R. State-of-the-article: distributed morphology. 1999. Disponível em: <http://linguistics.arizona.edu/ hharley/PDFs/HarleyNoyerDM1999.pdf>. Acesso em: 12 mar. 2003.

HEIM, I.; KRATZER, A. Semantics in generative grammar. Oxford: Blackwell Publishing, 1998.

HOUAISS, A. Dicionário Houaiss eletrônico da língua portuguesa. Rio de Janeiro: Objetiva, 2009.

KRATZER, A. Building statives. 2000. Disponível em: <http://semanticsarchive. net/Archive/GI5MmIOM/kratzer.building.statives.pdf>. Acesso em: 18 abr. 2003.

Severing the external argument from its verb. Phrase structure and the lexicon. Dodrecht: Kluwer Academic Publishers, 1996. p.109-137.

LIN, J. Event structure and the encoding of arguments: the syntax of the mandarin and english verb phrase. 2004. 194f. Thesis (Doctor of Linguistics) - MIT, Cambridge, 2004.

MARANTZ, A. Restitutive re- and the first phase syntax/semantics of the VP. New York: New York University, 2007. Não publicado.

. Argument structure and morphology: noun phrases that name events. New York: New York University, 2006. Não publicado.

. Words. MIT, 2001. Não publicado.

. Morphology as syntax: paradigms and the ineffable (the incomprehensible and unconstructable). MIT, 1999. Não publicado.

No escape from syntax: don't try morphological analysis in the privacy of your own lexicon. In: DIMITRIADIS, A.; et al. In: Annual Penn Linguistics Colloquium, 21., 1997, Pennsylvania. Proceedings... Pennsylvania: University of Pennsylvania, 1997. p.201-225, v.4.2.

MARVIN, T. Topics in the stress and syntax of words. 2002. 174f. Thesis (Doctor of Linguistics) - MIT, Cambridge, 2002.

MEDEIROS, A. B. Para uma abordagem sintático-semântica do prefixo des-. Revista da Abralin, Brasília, v.9, n.2, p.95-121, 2010. 
PARSONS, T. Events in the semantics of english: a study in subatomic semantics. Cambridge: MIT Press, 1990.

PESETSKY, D. Zero syntax: experiencers and cascades. Cambridge: MIT Press, 1995.

RAMCHAND, G. Verb meaning and the lexicon: a first-phase syntax. Cambridge: Cambridge University Press, 2008.

SCHER, A. P.; MEDEIROS, A. B.; MINUSSI, R. D. Estrutura argumental em morfologia distribuída. In: NAVAES, R.; LIMA-SALLES, H. M. M. (Org.). Estudos formais da gramática das línguas naturais. Brasília: Cânone, 2012. p.175-197.

STECHOW, A. The different readings of wieder 'again': a structural account. Journal of SemanticS, Oxford, n.13, v.2, p.87-138, 1996.

TENNY, C. Aspectual roles and the syntax-semantics interface. Dordrecht: Kluwer Academic Publushers, 1994.

WILLIAMS, E. Telic too late. Cambridge: Harvard University, 2006. Não publicado.

Recebido em 25 de setembro de 2011.

Aprovado em 20 de agosto de 2012. 